\title{
Meteors and meteorite falls in Morocco
}

\author{
Abderrahmane Ibhi \\ Laboratory of Geo-heritage and Geo-materials Science, Ibn Zohr University, Agadir, Morocco \\ E-mail address: a.ibhi@uiz.ac.ma
}

\begin{abstract}
During the last eighty years, thirteen meteorite falls were recorded in Morocco, which ten are well documented and named Douar Mghila, Oued el Hadjar, Itqiy, Zag, Bensour, Oum Dreyga, Benguerir, Tamdakht, Tissint and Aoussred. It represent only $0.011 \%$ of the Moroccan declared meteorites.The authenticated observed falls represent three types of different meteorites, eight ordinary chondrites (Four of type LL, three of type $\mathrm{H}$ and one of type $\mathrm{EH}$ ), one carbonaceous chondrite and one Shergottite basaltic achondrites. The Morocco meteorite fall recovery rate, during the past eighty years, is low 0.11 falls per year on average per $2.11 \mathrm{~km}^{2}$ (or approximately one fall recovery per 10 year time interval).
\end{abstract}

Keywords: Meteor; meteorite; fall; bright bolide; Morocco

\section{INTRODUCTION}

As samples from minor planets, meteorites are an unique source of information about a wide variety of events that occurred very early in the history of the solar system and meteorite fall statistics are frequently used by planetary scientists to approximate the true flux of meteorites on the Earth.

Well documented meteorite falls provide the best available measure of the relative abundances of the different types of meteorite that survive their fall to Earth. The aim of statistical studies is to obtain reliable alues for the influx of meteorite falls and their mass and the constitution of the meteoritic flux. Wickman and Palmer [1] have shown that statistics based on witnessed falls and chance recoveries are fraught with difficulties, and generally rely on ad hoc assumptions about how the distribution of human populations around the world, and their varying levels of education, affect the probability of meteorite recognition and recovery.

This article lists by chronological order every meteor fall observed in Morocco and well documented. All those objects have been watched by eyewitnesses, as it moved in the atmosphere or touched the ground. At the end of May 2012, thirteen official records for observed meteorite falls from Morocco. Moroccan falls are listed and their geographical distribution is shown in Fig. 1. 


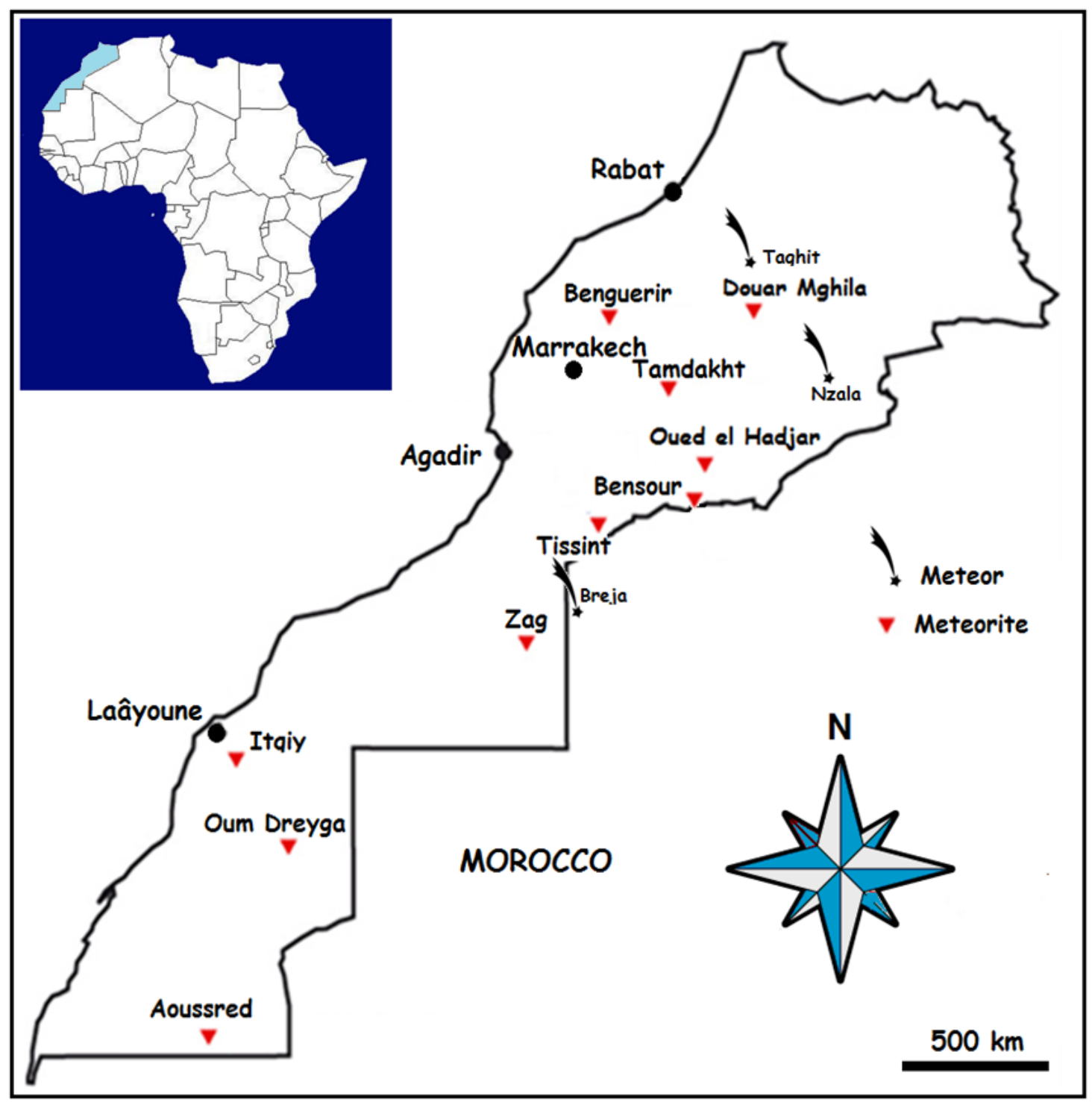

Fig. 1. Map showing the distribution of meteorite falls from Morocco.

\section{COLLECTING OBSERVATIONS}

\section{1. Meteorites}

The list by chronological order of all meteor falls observed in Morocco and documented (Fig. 2). All those objects have been watched by eyewitnesses and all last Moroccan falls have been recovered by hunters that spend a lot of time searching meteorites especially in the desert.

1- Douar Mghila. (1932, Ordinary chondrite LL6), some kind of a rocket, from East to west, has been seen through the sky. It has been accompanied with a detonation that we compared with a gun and was heard $10 \mathrm{~km}$ from the region, where fell forty stones. According to Captain Larcher, who has witnessed this phenomenon, it occurred $4 \mathrm{~km}$ east of Beni Mellal (Douar Mghila) [2]. 
2- Oued el Hadjar. (1986, Ordinary chondrite LL6), nomads heard a loud whistle and saw a $1215.5 \mathrm{~g}$ stone fall $200 \mathrm{~m}$ from their tent. The stone was broken into many pieces, during a wedding ceremony [3].

3- Itqiy. (1990, Ungrouped enstatite-rich meteorite), after a detonation and the appearance of light, one stone of $410 \mathrm{~g}$ was recovered near Itqiy by a nomad. A larger stone weighing 4310 g was recovered by Marc Luc and Jim Labenne while searching for meteorites in the same place in 2000 July [3].

4- Zag. (1998, Ordinary chondrite H3-6), a meteorite fall was witnessed on a mountain in the vicinity of Zag, Morocco. About $175 \mathrm{~kg}$ have been sold by local people to dealers and collectors under the names Zag, Sagd, and Tan-Tan [3].

5- Bensour. (2002, Ordinary chondrite LL6), eyewitness accounts from several nomads in the border region of Morocco and Algeria attest to a significant fall of many individual stones. However these reports are not detailed. Total weight is estimated to be in excess of $45 \mathrm{~kg}$, the largest being a 9.2 kilogram individual which broke into 3 large pieces on impact [4].

6- Oum Dreyga. (2003, Ordinary chondrite H3-5), moroccan soldiers stationed in Western Sahara saw a meteorite falling on Gour Lafkah Mountains, south of Zbayra, about $21 \mathrm{~km}$ from Oum Dreyga. The meteorite fell near a $670 \mathrm{~km}$ long wall built in 1985, protected by antipersonnel mines, and guarded by soldiers. Some fragments have been picked up soon after the fall. About $17 \mathrm{~kg}$ were recovered. Fragments have been sold under the names Amgala and Gor Lefcah [5].

7- Benguerir. (2004, Ordinary chondrite LL6), a meteorite shower was witnessed to fall near Benguerir ( $\sim 50 \mathrm{~km}$ due north of Marrakesh) by local people. The fall had an east-to-west trajectory. The estimated total recovered mass is $\sim 25-30 \mathrm{~kg}[5]$.

8- Tamdakht. (2008, Ordinary chondrite H5), the witnesses from a number of locations in Morocco (Agadir, Marrakesh, Ouarzazate) observed a meteor with a west to east trajectory. People from the high Atlas Mountains (between Marrakesh and Ouazazate) heard a sound and felt an aftershock [6].

9- Tissint. (2011, Shergottite), a meteoritic body entered the earth's atmosphere in the southeast skies of Tata, Morocco. Its interaction with the atmosphere led to brilliant light flashes accompanied with detonations. The apparent magnitude of the fireball was brighter than -20 . A large number of fragments survived the fireball phenomena $[7,8]$.

10- Aoussred. (2012, Carbonaceous chondrite CH), according to one of the three eyewitnesses to the spectacle offered by the entry into the atmosphere of the meteorite, the first ball was white orange before turning red, illuminating the entire area and breaking into pieces after a large explosion. The first fragment was discovered by a soldier who then contacted A. Ibhi, professor at the University Ibn Zohr Agadir [9]. 


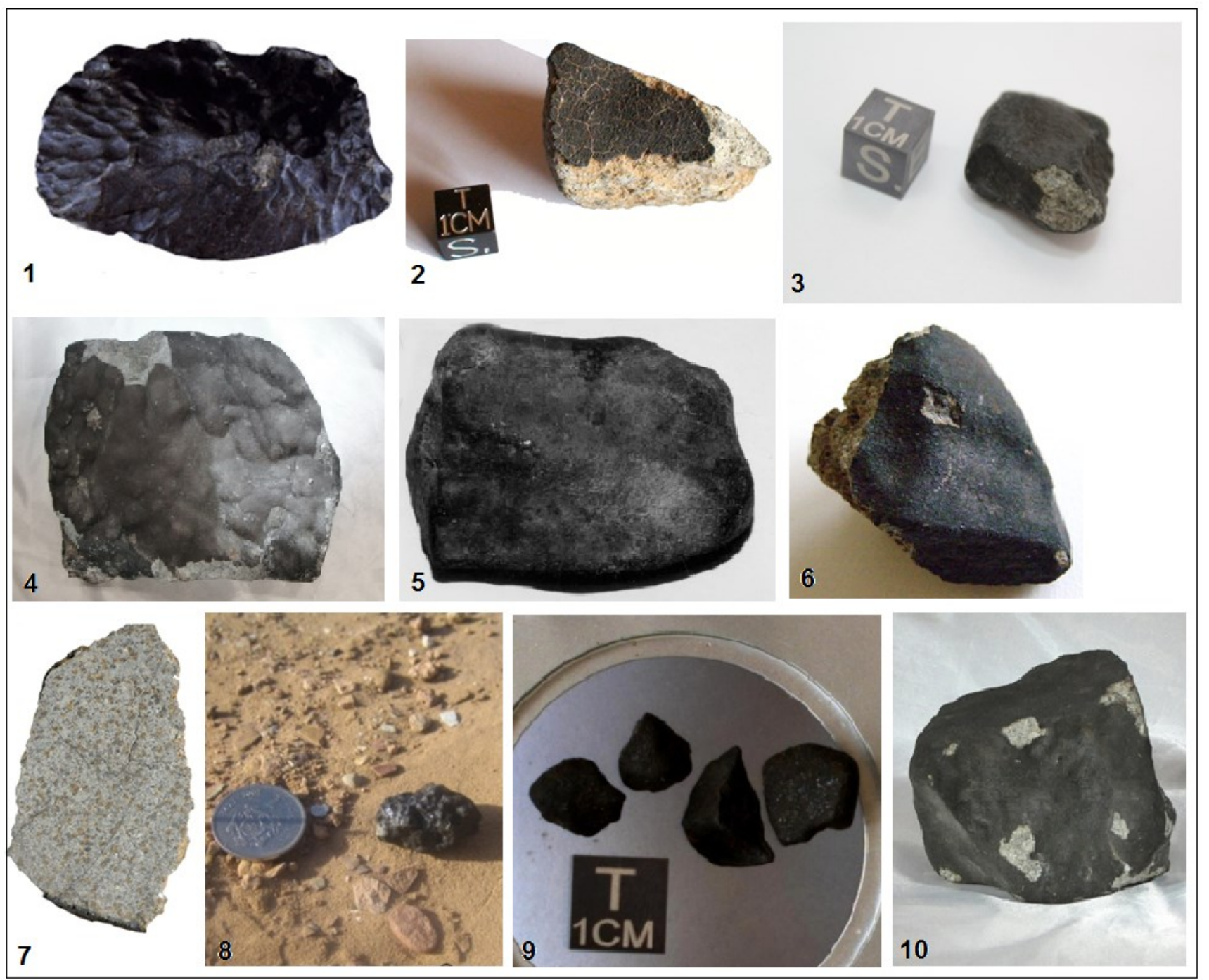

Fig. 2. Meteorite falls from Morocco 1. Douar Mghila (640.85 grams CMNHNP); 2. Oued el Hadjar (24.78 grams, CMeteorite.fr); 3. Benguerir (17 grams, CIbhi A.); 4. Tamdaght (210 grams,

(CLangheinrich meteorites); 5. Itqiy (475.25, CLabenne meteorites); 6. Oum Dreyga (52 grams, (C)Allmeteorite); 7. Zag (45 grams, CMichel Franco); 8. Tissint (5.3 grams, CIbhi A.); 9. Aoussred (24 grams, CIbhi A.); 10. Bensour (342 grams, CLangheinrich meteorites).

\section{2. Strewn field}

In these 10 falls only two who beneficed study strewn field, Tissint and Tamdakht meteorites (Fig. 3).The Tissint strewn field of this meteorite fall extends at least $15 \mathrm{~km}$ from the west-north-west to east-south-east, which is also the flight direction of the meteorite after the observations of the nomads. More than 50 fragments of Tissint meteorite weighing about $20 \mathrm{~kg}$ have been recovered from the strewnfield of $60 \mathrm{~km}^{2}$ area [8].

Approximate trajectory of the Tamdaght strewn field, according to eye witness reports and meteorite find location according to finder's GPS data given in red, is about $25 \mathrm{~km}$ long and $2 \mathrm{~km}$ wide [6]. The horizontal trajectory, shallow impact pits in the loose gravel soil and the total destruction of masses that did not impact rock but clay surfaces, may provide 
evidence that the meteorites did retain at least some of their cosmic velocity until they hit the ground at an altitude of 1500 meters.
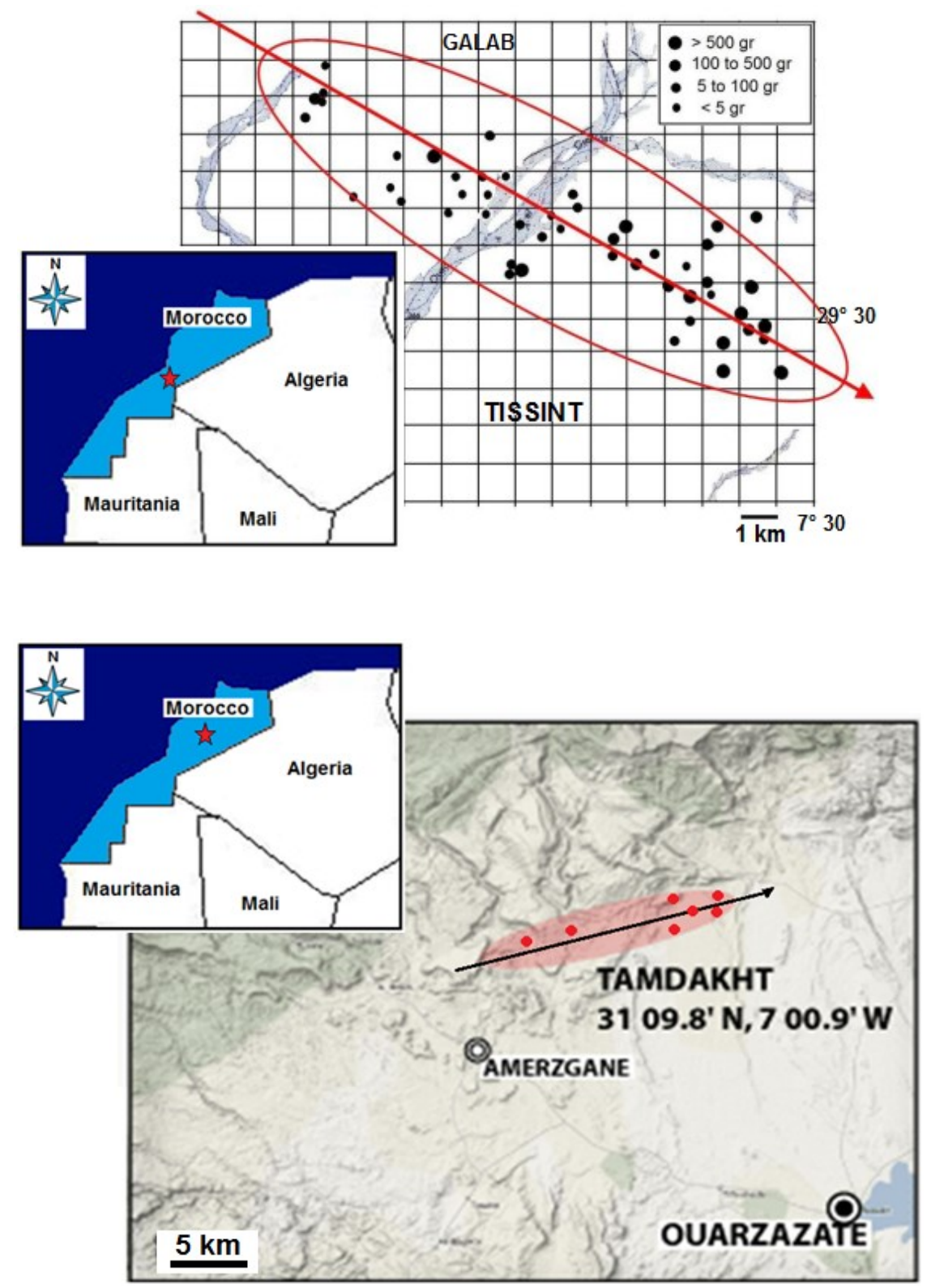

Fig. 3. Tissint and Tamdakht strewn fields.

\subsection{Meteors}

The falls of Breja, Nzala and Taouz (Fig. 1) by opposition to the other witnessed falls, raises a problem in the exactness of the statements which relate to it. In spite of eyewitnesses' presence, it always misses in the declaration of this fall the essential elements as the exact coordinates and even the precise day of the fall. As the meteors observations are not precise, the research is not always successful and they can spend weeks and months in the field without recovering the meteorite. While there will always be an element of luck involved in 
meteorite fall recovery, a nighttime fireball, after all, will be visible over a much larger geographical region than that in which the meteorite physically falls.

1- Breja. (2010, LL6 ordinary chondrite), May $1^{\text {st }}$ at 3:00 GMT in the area of Breja, $35 \mathrm{~km}$ north of Tindouf and east of Zag, many people witnessed a very bright bolide accompanied by a sonic boom and fragmentation event. Nomads recovered the meteoritic material in the border to Morocco.

2- Nzala. (2009, Ordinary chondrite), November $13^{\text {th }}$ at 21:00 GMT, many people from Erfoud, Errachidia and Errich (Morocco) observed the meteor and heard three sonic booms. Meteorite hunters searched for weeks but no sample has been found except one report from a dealer about nomads who found two pieces of about 100 and 700 grams.

3- Taouz. (2010, no sample has been recovered so far), May 19th at 4:00 GMT. In Taouz area, a few eyewitnesses reported the high brightness meteor and a sound like many rocks fall. At the same date and hour, people from Taghit in Algeria reported a similar observation.

Below, is complete list of the well-documented meteorite falls (Table 1), showing the name of the meteorite, the date it fell, the place of fall, and the type of meteorite. Also, meteors are named after the place they fell.

Table 1. Meteors* and meteorite falls in Morocco.

\begin{tabular}{|c|c|c|c|c|c|}
\hline Year & Name & GPS & Date & Type & Weight \\
\hline 1932 & Douar Mghila & $32^{\circ} 20^{\prime} \mathrm{N} / 6^{\circ} 18^{\prime} \mathrm{W}$ & August 20, 1932 & LL6 & $1161 \mathrm{~g}$ \\
\hline 1986 & Oued el Hadjar & $30^{\circ} 10^{\prime} 48^{\prime \prime} \mathrm{N} / 6^{\circ} 34^{\prime} 38^{\prime \prime} \mathrm{W}$ & March, 1986 & LL6 & $1216 \mathrm{~g}$ \\
\hline 1990 & Itqiy & $26^{\circ} 35^{\prime} 27^{\prime \prime} \mathrm{N} / 12^{\circ} 57^{\prime} 8^{\prime \prime} \mathrm{W}$ & March 1990 & EH7 & $4.72 \mathrm{~kg}$ \\
\hline 1998 & Zag & $27^{\circ} 20^{\prime} \mathrm{N} / 9^{\circ} 20^{\prime} \mathrm{W}$ & August 4 or 5,1998 & H3-6 & $175 \mathrm{~kg}$ \\
\hline 2002 & Benssour & $30^{\circ} \mathrm{N} / 7^{\circ} \mathrm{W}$ & $\begin{array}{c}\text { February } 11 \text { at } 4: 30 \\
\text { GMT } \\
\end{array}$ & LL6 & $\sim 45 \mathrm{~kg}$ \\
\hline 2003 & Oum Dreyga & $24^{\circ} 18^{\prime} \mathrm{N} / 13^{\circ} 6^{\prime} \mathrm{W}$ & October 16, 2003 & H3-5 & $17 \mathrm{~kg}$ \\
\hline 2004 & Benguerir & $\begin{array}{c}32^{\circ} 13^{\prime} 52.9^{\prime \prime} \mathrm{N} / 8^{\circ} 8^{\prime} 56.7^{\prime \prime} \\
\mathrm{W}\end{array}$ & $\begin{array}{c}\text { November 22, at } \sim 11: 45 \\
\text { GMT }\end{array}$ & LL6 & $25-30 \mathrm{~kg}$ \\
\hline 2008 & Tamdakht & $31^{\circ} 9^{\prime} 48^{\prime \prime} \mathrm{N} / 7^{\circ} 0^{\prime} 54^{\prime \prime} \mathrm{W}$ & $\begin{array}{c}\text { December 20, at 22:37 } \\
\text { GMT }\end{array}$ & H5 & $\sim 100 \mathrm{~kg}$ \\
\hline 2011 & Tissint & $\begin{array}{c}29^{\circ} 28.917^{\prime} \mathrm{N} / \\
7^{\circ} 36.674^{\prime} \mathrm{W}\end{array}$ & July 18 , at 2:10 GMT & Shergottite & $20 \mathrm{~kg}$ \\
\hline 2012 & Aoussred & $\begin{array}{l}22^{\circ} 18^{\prime} 34^{\prime \prime} \mathrm{N} / \\
14^{\circ} 06^{\prime} 293 \mathrm{~W}\end{array}$ & May 20, at $22: 45$ GMT & $\mathrm{CH}$ & $270 \mathrm{~g}$ \\
\hline 2009 & Nzala* & - & $\begin{array}{c}\text { November } 13^{\text {th }} \text { at 21:00 } \\
\text { GMT }\end{array}$ & OC? & $\sim 1200 \mathrm{~g}$ \\
\hline 2010 & Taouz* & - & May 19th at 4:00 GMT & - & - \\
\hline 2010 & Breja* & - & May 1st, at 3:00 GMT & LL6 & $16 \mathrm{~kg}$ \\
\hline
\end{tabular}


Table 1 shows an uneven distribution in time. It is quite clear that between 2003 and 2012 (9 years 5 was recovered meteorites). It is reasonably clear, therefore, that the most dramatic times for meteorite recovery in Morocco stretched from 1932 to 1998 . Why was this time interval so productive with respect to meteorite falls? Some of the answer to this question lies behind the establishment of the Geoheritage and geomaterials laboratory (Ibn Zohr University); the time interval corresponds to the period when a strong meteorite recovery group operated from within Geoheritage and geomaterials laboratory. Indeed, the Loboratory team of field researchers, headed by geologist A. Ibhi, was directly involved in the recovery of the Benguerir (2004), Tamdakht (2008), Tissint (2011) and Aoussred (2012) meteorites [79].

\section{STATISTICAL STUDY OF OBSERVED METEORITE FALLS IN MOROCCO}

In Morocco there have been a total of 10 meteorite falls in the time interval 1932 to 2012. It represent only $0.011 \%$ of the Moroccan declared meteorites. The first fall in Morocco was the Douar Mghila meteorite (LL6, 1161 grams; Table 1); the last fall was the Aoussred meteorite $(\mathrm{CH}, 370$ grams; Table 1). The Morocco meteorite fall recovery rate, during the past 80 years, is low 0.11 falls per year on average (or approximately one fall recovery per 10 year time interval, or equivalently, 0.1 fall per year per $2.11 \mathrm{~km}^{2}$ ). The reasons why so few meteorite falls are recovered per year are no-doubt many and complex. Rasmussen [10] has discussed a number of the possible reasons why the meteorite recovery rate and the documentation of fireball observations Worldwide (have varied with time). A short list of possible factors includes the non-uniform distribution of people, the required development of a scholarly community interested in investigating falls and wars. The list is not quite endless, but it could certainly go on to include geographical conditions in the fall area and weather factors [11].

\section{DISCUSSION AND CONCLUSION}

Observed meteorite falls are interesting for several reasons. Material from observed falls has not been subjected to terrestrial weathering, making the find a better candidate for scientific study. Historically, observed falls were the most compelling evidence supporting the extraterrestrial origin of meteorites. Furthermore, observed fall discoveries are a better representative sample of the types of meteorites which fall to Earth.

Ten observed falls have been recovered in Morocco. The earliest well-documented meteorite fall occurred in 1932 near Douar Mghila from which hundreds of stones were collected [2]. The most recently recovered fall, a single stone weighing 270 grams, occurred on 20 May, 2012 at Aoussred in Morocco western Sahar [9]. The authenticated observed falls comprise eight ordinary chondrites (Four of type LL, three of type $\mathrm{H}$ and one of type EH), one carbonaceous chondrite and one Shergottite basaltic achondrite.

A number of other fresh meteorite recoveries in Morocco have been linked to witnessed fireballs (e.g., Breja, Nzala and Taouz), these meteorites were found or recognized some time after the reported events and their dates of fall have to be considered doubtful.

Most Morocco meteorites that remain in the country are held in a few institutional collections. The largest collection of Morocco meteorites is held by the Department of Geology in Ibn Zohr University $[12,13]$. 


\section{References}

[1] Wickman F. E., Palmer C. D., Proceedings of the Indian Academy of Sciences 88 (1979) 247-272.

[2] Lacroix M. A., Comptes rendus hebdomadaires des séances de l'Académie des Sciences T197 (1933) 368-369.

[3] Grossman J. N., Zipfel J., Meteoritics \& Planetary Science 36 (2001) 293-322.

[4] Russell S. S., Folco L., Grady M. M., Zolensky M. E., Jones R., Righter K., Zipfel J., Grossman J. N., Meteoritics \& Planetary Science 398 (2004) 215-272.

[5] Russell S. S., Zolensky M., Righter K., Folco L., Jones R., Connolly H. C., Grady J. M., Grossman J. N., Meteoritics \& Planetary Science 409 (2005) 201-263.

[6] Weisberg M. K., Smith C., Benedix G., Folco L., Righter K., Zipfel j., Yamaguchi A., Aoudjehane H., Meteoritics \& Planetary Science 443 (2009) 1-33.

[7] Ibhi A., Meteorite 18(2) (2012) 9-12.

[8] Ibhi A., Astronomie 48 (2012) 52-55.

[9] Ait Kadi M., Bulletin d'Information de l'Académie Hassan II des Sciences et Techniques 12 (2012) 106-108.

[10] Rasmussen K. L., Quarterly Journal of the Royal Astronomical Society 31 (1990) 95-108.

[11] Beech M., Journal of the Royal Astronomical Society of Canada 97 (2003) 71-77.

[12] Abderrahmane Ibhi, International Letters of Chemistry, Physics and Astronomy 11 (2013) 20-25.

[13] Hassane Nachit, Abderrahmane Ibhi, Carmela Vaccaro, International Letters of Chemistry, Physics and Astronomy 11 (2013) 65-71. 